\title{
Chewed or Crushed Administration of Adenosine Diphosphate Receptor Inhibitors in Acute Coronary Syndromes: a Systematic Review and Meta-analysis of Randomized Controlled Trials
}

\author{
Hourmazd Haghbayan ${ }^{1,2}$ (D) Bishoy Deif $^{1} \cdot$ Eric A. Coomes ${ }^{3}$ \\ Published online: 4 September 2019 \\ (C) Springer Science+Business Media, LLC, part of Springer Nature 2019
}

\section{Introduction}

In patients with acute coronary syndromes (ACS) undergoing primary percutaneous coronary intervention (PCI), the rapid administration of adenosine diphosphate (ADP) receptor inhibitors is indicated for the prevention of peri- and postprocedural thrombotic events. Although newer agentsticagrelor and prasugrel-improve clinical outcomes in this population via a more rapid and potent inhibition of platelet reactivity $[1,2]$, their time to peak effect still requires several hours $[3,4]$. Small trials have studied the chewed or crushed administration of these drugs compared with whole tablets, but the pooled effect of such a strategy on platelet reactivity has not been systematically assessed in an ACS population.

\section{Methods}

We performed a systematic review and meta-analysis of randomized trials comparing the administration of oral ADP receptor inhibitors chewed or crushed vs. swallowed whole in adults with ACS. We searched MEDLINE and EMBASE from inception to June 2019, employing keyword and indexterm clusters linking ADP receptor inhibitors, ACS, and administration methods. Two reviewers independently

Hourmazd Haghbayan

hourmazd.haghbayan@mail.utoronto.ca

1 Division of Cardiology, University Hospital, London Health Sciences Centre, Western University, Room C6-004, 339 Windermere Road, London, Ontario N6A 5A5, Canada

2 Department of Social and Preventive Medicine, Université Laval, Quebec City, Québec, Canada

3 Department of Medicine, University of Toronto, Toronto, Ontario, Canada undertook study selection and data abstraction, with conflicts arbitrated by a third reviewer. Our primary outcomes were pharmacodynamic measurements of platelet reactivity (P2 $\mathrm{Y}_{12}$ reaction units, PRUs); secondary outcomes encompassed all thrombotic, bleeding, and other safety events (dyspnea and symptomatic bradycardia) reported by the primary studies. Inverse-variance meta-analysis of mean differences (MD) was undertaken using random effects models with 95\% confidence intervals (95\% CI) at all time points for which data were reported in $\geq 2$ studies. Analyses were performed using Review Manager version 5.3 (Copenhagen, Cochrane Collaboration).

\section{Results}

Following screening of 103 citations, 24 were evaluated in full text, and five studies $(n=251)$ were eligible [5-9]. Study designs and patient characteristics are summarized (Table 1); all but one trial studied ticagrelor, mean age was 59 years, and 95\% underwent PCI. As compared with swallowing tablets whole, patients randomized to chewed or crushed administration of ADP receptor inhibitors had significantly lower PRUs at $0.5 \mathrm{~h}\left(\mathrm{MD}=-48.3 ; 95 \% \mathrm{CI},-75.1--21.2 ; I^{2}=0 \%\right), 1 \mathrm{~h}$ $\left(\mathrm{MD}=-82.5 ; 95 \% \mathrm{CI},-103.8--61.2 ; I^{2}=0 \%\right), 2 \mathrm{~h}(\mathrm{MD}=$ $\left.-31.5 ; 95 \% \mathrm{CI},-62.6-0.37 ; I^{2}=15 \%\right)$, and $4 \mathrm{~h}(\mathrm{MD}=-$ $16.4 ; 95 \% \mathrm{CI},-32.8--0.04 ; I^{2}=16 \%$ ), indicating greater platelet inhibition following chewed or crushed administration of the drug (Fig. 1).

Four studies reported clinical outcomes [5-8], which found that thrombotic events did not differ significantly between the chewed/crushed and whole tablet arms $(0.8 \%$ vs. $1.6 \%, p=$ $0.66)$; similarly, safety outcomes including minor bleeding, dyspnea, and symptomatic bradycardia did not differ significantly $(12.7 \%$ vs. $8.8 \%, p=0.36)$. No episodes of major bleeding occurred. 


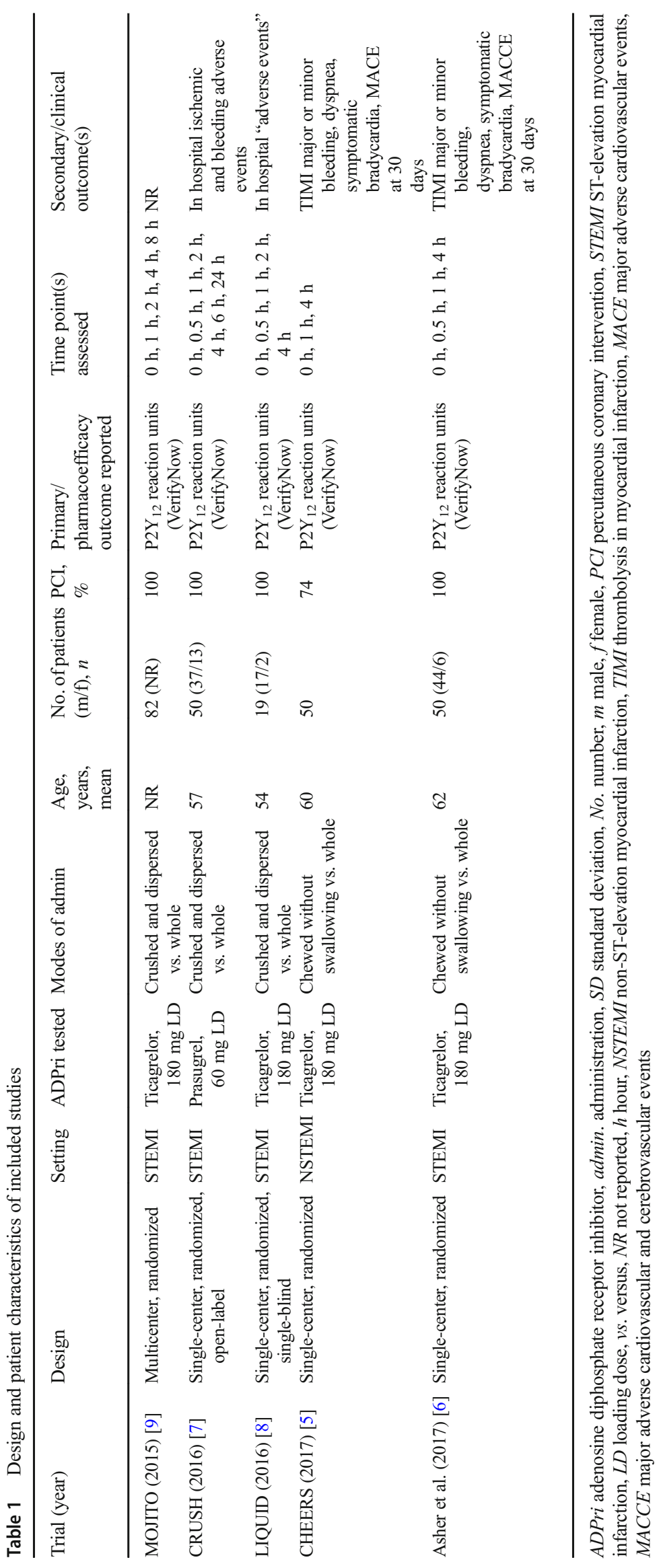




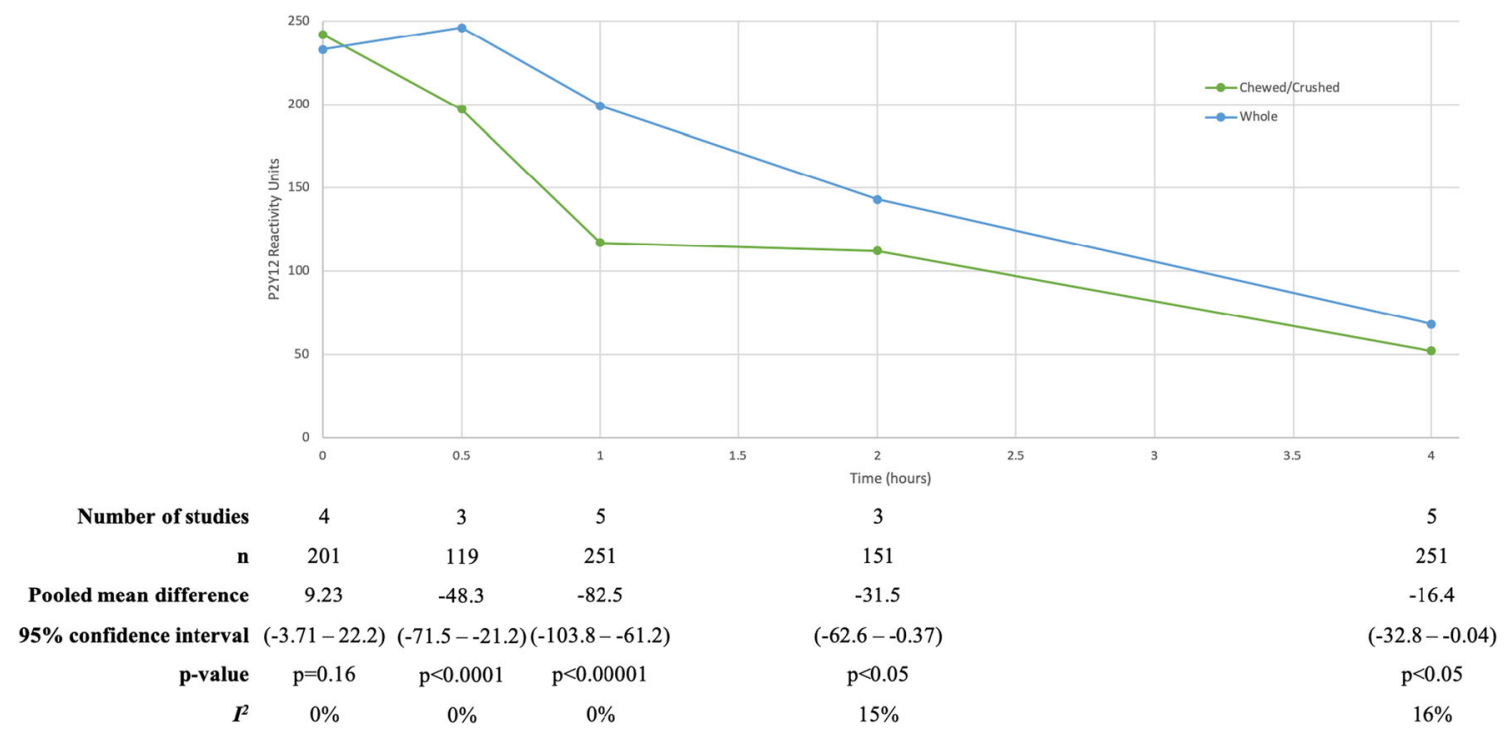

Fig. 1 Meta-analysis of platelet reactivity over time in patients with acute coronary syndrome administered adenosine diphosphate receptor inhibitors crushed or chewed vs. swallowed whole

\section{Discussion}

In this meta-analysis of randomized trials, we found that the administration of chewed or crushed ADP receptor inhibitors in the ACS setting permits significantly faster platelet inhibition than the conventional administration of whole tablets. This difference is seen as early as $30 \mathrm{~min}$ following the loading dose, with a $19.3 \%$ relative reduction in platelet activity, reaches a peak of over $40 \%$ reduction at $1 \mathrm{~h}$, and continues to persist significantly up to the $4 \mathrm{~h}$ mark. Despite pooling data across studies, this meta-analysis likely remains underpowered for the detection of differences in clinical outcomes, such as thrombosis. However, no early signal of increased harm (such as bleeding, dyspnea, or symptomatic bradycardia) was found in our assessment of safety outcomes.

Rapid and effective platelet inhibition is crucial in ACS, especially amongst STEMI patients planned for primary PCI in whom procedural thrombotic risk must be mitigated. The ATLANTIC trial demonstrated that the prehospital administration of ticagrelor at a median of $31 \mathrm{~min}$ sooner than at the time of catheterization resulted in a large reduction in the rate of stent thrombosis [10]. As our analyses demonstrate that chewing or crushing ADP receptor inhibitors produces significantly greater platelet inhibition as early as 30 min following administration, this may indicate the potential for similar clinical benefit. These findings warrant further evaluation via a larger trial powered to detect differences in thrombotic outcomes.

Contributor Statement H.H. designed the study, undertook the literature search, analyzed the data, and wrote the manuscript. H.H. and B.D. undertook study selection. H.H. and E.A.C. undertook data abstraction. All authors interpreted the data and edited the manuscript critically for important intellectual content.

\section{Compliance with Ethical Standards}

Conflict of Interest The authors declare that they have no conflict of interest.

\section{References}

1. Wallentin L, Becker RC, Budaj A, Cannon CP, Emanuelsson H, Held C, et al. Ticagrelor versus clopidogrel in patients with acute coronary syndromes. N Engl J Med. 2009;361(11):1045-57.

2. Wiviott SD, Braunwald E, McCabe $\mathrm{CH}$, et al. Prasugrel versus clopidogrel in patients with acute coronary syndromes. N Engl J Med. 2007;357(20):2001-15.

3. Parodi G, Valenti R, Bellandi B, Migliorini A, Marcucci R, Comito $\mathrm{V}$, et al. Comparison of prasugrel and ticagrelor loading doses in ST-segment elevation myocardial infarction patients: RAPID (rapid activity of platelet inhibitor drugs) primary PCI study. J Am Coll Cardiol. 2013;61(15):1601-6.

4. Alexopoulos D, Xanthopoulou I, Gkizas V, Kassimis G, Theodoropoulos KC, Makris G, et al. Randomized assessment of ticagrelor versus prasugrel antiplatelet effects in patients with STsegment-elevation myocardial infarction. Circ Cardiovasc Interv. 2012;5(6):797-804.

5. Asher E, Frydman S, Katz M, Regev E, Sabbag A, Mazin I, et al. Chewing versus swallowing ticagrelor to accelerate platelet inhibition in acute coronary syndrome - the CHEERS study. For the PLATIS (platelets and thrombosis in sheba) study group. Thromb Haemost. 2017;117(4):727-33.

6. Asher E, Tal S, Mazin I, Abu-Much A, Sabbag A, Katz M, et al. Effect of chewing vs swallowing ticagrelor on platelet inhibition in patients with ST-segment elevation myocardial infarction: a randomized clinical trial. JAMA Cardiol. 2017;2(12):1380-4.

7. Rollini F, Franchi F, Hu J, Kureti M, Aggarwal N, Durairaj A, et al. Crushed prasugrel tablets in patients with STEMI undergoing primary percutaneous coronary intervention: the CRUSH study. $J$ Am Coll Cardiol. 2016;67(17):1994-2004.

8. Alexopoulos D, Barampoutis N, Gkizas V, Vogiatzi C, Tsigkas G, Koutsogiannis N, et al. Crushed versus integral tablets of ticagrelor 
in ST-segment elevation myocardial infarction patients: a randomized pharmacokinetic/pharmacodynamic study. Clin Pharmacokinet. 2016;55(3):359-67.

9. Parodi G, Xanthopoulou I, Bellandi B, Gkizas V, Valenti R, Karanikas $\mathrm{S}$, et al. Ticagrelor crushed tablets administration in STEMI patients: the MOJITO study. J Am Coll Cardiol. 2015;65(5):511-2.
10. Montalescot G, van 't Hof AW, Lapostolle F, Silvain J, Lassen JF, Bolognese L, et al. Prehospital ticagrelor in ST-segment elevation myocardial infarction. N Engl J Med. 2014;371(11):1016-27.

Publisher's Note Springer Nature remains neutral with regard to jurisdictional claims in published maps and institutional affiliations. 